\title{
Transformación y crisis de la escuela: algunas reflexiones sobre el caso colombiano
}

\author{
Nancy Palacios Mena ${ }^{1}$ \\ Institución Educativa Santa Ana de los Caballeros (Colombia) \\ Universidad del Tolima. CREAD Pereira \\ nancypalacios26@hotmail.com
}

Recepción: 13/03/2013

Evaluación: 31/05/2013

Aceptación: 28/06/2013

Artículo de Revisión

DOI: http:/ / dx.doi.org/ 10.9757/ Rhela. 21.11

\section{RESUMEN}

La escuela ya no es la institución formadora por excelencia y aquello que plantea el ideal de educación no necesariamente es lo que ocurre en los establecimientos educativos, la relación entre las concepciones y las formas de funcionamiento de la disciplina, la norma y la democracia son claves en la organización social de las instituciones, puesto que aquellas donde existe relativa coherencia entre el discurso y la práctica y claridad en los principios y planteamientos esenciales que fundamentan su funcionamiento tienen mayor capacidad de resolver los conflictos que puedan surgir entre los actores que en ellas se relacionan.

En su creación, la escuela fue concebida como una institución que debía asegurar simultáneamente la integración a la sociedad y la promoción del individuo, este modelo de escuela se caracterizó por un conjunto de principios y valores concebidos como sagrados, que además no tenían por qué ser justificados. Pero cambios en la sociedad, la introducción de nuevas ideologías y estilos de vida, así como cambios en la manera de relacionarse, de actuar y de pensar de los miembros de la misma escuela, la diversificación de la oferta escolar, la multiplicación de establecimientos, la masificación de la educación, las divergencias en la manera de pensar y de actuar de los docentes estudiantes y personal directivo de las instituciones hicieron que los principios estructuradores que sustentan a la institución escolar hoy sean percibidos como inciertos y contradictorios.

Las funciones de la escuela se han desarticulado y la utilidad social de los estudios, sus finalidades culturales y sus modos de control ya no son compartidos por quienes conviven en las escuelas y colegios, los cambios que se han dado en las últimas décadas en la organización social de la escuela y por ende, en las relaciones entre sus miembros, hacen parte de un modo de funcionamiento en el cual, esta ya no puede ser concebida como un sistema unificado sino como un espacio donde hay divergencias $y$ convergencias entre sus miembros, tanto en la manera de pensar como en la de actuar.

Palabras clave: Revista Historia de la Educación Latinoamericana, escuela, crisis, transformación, disciplina, norma, democracia.

1 Magíster en Sociología de la Universidad del valle, docente ciencias sociales en educación básica y media en instituciones educativas de Cali y Ansermanuevo Valle del Cauca, docente del programa de licenciatura en pedagogía infantil de la universidad del Tolima CREAD Pereira. 


\section{Transformation and crisis of the school: Some reflections on the Colombian case}

\author{
Transformação e crise da escola: algumas \\ reflexões sobre o caso colombiano
}

\section{ABSTRACT}

The school is not any more a development institution for excellence and what sets out the ideal of education is not necessarily what happens in educational establishments, the relationship between the concepts and working ways of the discipline, the rule and democracy are the keys to the social organization of the institutions: because those where there is a relative coherence between discourse and practice and clarity in the essential approaches that underlie its operation, they have a greater capacity to resolve conflicts that may arise between the actors in their interior relate.

In this inception, the school was conceived as an institution that should ensure simultaneously the integration into the society and the promotion of the individual. This school model was characterized by a set of principles and values designed as sacred, that also they did not have for what being well-taken. The changes in the society, the introduction of new ideologies and life styles, as well as changes in the way of being related, of acting and of thinking about the members of the same school, the diversification of the school offer, the multiplication of establishments, the overcrowding of the education, the differences in the way of thinking and of acting of the teaching students, and managing personnel of the institutions, they did that beginners in structuralism who sustain the school institution today are perceived as uncertain and contradictory.

The functions of the school have been dismantled and the social utility of the studies, its cultural purposes and its ways of control are not already shared for whom they coexist in the schools, thus the changes that have happened in last decades in the social organization of the school and so, in the relations between its members, take part of a way of working in which it is already it cannot be conceived as a unified system, but as a space where there are differences and convergences between its members, specifically in the way of thinking as in that of acting.

\section{RESUMO}

A escola já não é a instituição formadora por excelência e aquilo que fundamenta o ideal de educação não necessariamente é o que ocorre nos estabelecimentos educativos. A relação entre as concepções e as formas de funcionamento da disciplina, a norma e a democracia são centrais na organização social das instituições, posto que aquelas nas quais que existe relativa coerência entre o discurso e a prática, e clareza nos princípios e planejamentos essenciais que fundamentam seu funcionamento, têm maior capacidade de resolver conflitos que possam surgir entre os sujeitos que em seu interior se relacionam.

Em sua criação, a escola foi concebida como uma instituição que devia assegurar simultaneamente a integração à sociedade e a promoção do indivíduo, este modelo de escola se caracterizou por um conjunto de princípios e valores concebidos como sagrados, que ademais não tinham porque serem justificados. Porém, mudanças na sociedade, a introdução de novas ideologias e estilos de vida, assim como mudanças nas formas de relacionar-se, de atuar e de pensar dos membros da mesma escola, a diversificação da oferta escolar, a multiplicação de estabelecimentos, a massificação da educação, as divergências na maneira de pensar e de atuar dos docentes, estudantes e pessoa diretivo das instituições, fizeram que os princípios estruturadores que sustentam a instituição escolar hoje sejam percebidos com incertos e contraditórios. As funções da escola se desarticularam e a utilidade social dos estudos, suas finalidades culturais e seus modos de controle já não são compartilhados por aqueles que convivem nas escolas e colégios, as mudanças que se deram nas últimas décadas na organização social da escola e, portanto, nas relações entre seus membros, fazem parte de um modo de funcionamento na qual esta já não pode ser concebida como um sistema unificado, senão como um espaço em que há divergências e convergências entre seus membros, tanto na maneira de pensar como na de atuar. 
Key words: Journal of the history of the Latin American education, school, crisis, transformation, discipline, rule, democracy
Palavras-chave: Revista História da Educação Latino-americana, escola, crises, transformação, disciplina, norma, democracia.

\section{INTRODUCCIÓN}

Este trabajo es un acercamiento a las dinámicas de funcionamiento de la escuela colombiana actual, a las maneras en las que se relacionan, en la cotidianidad de los establecimientos educativos, estudiantes, docentes, directivos y padres de familia.

El estudio intenta sustentar que algunos trabajos de investigación realizados en los últimos veinte años del siglo pasado sobre la vida escolar en Colombia, que concluyeron que la escuela era autoritaria, injusta y violatoria de los derechos de los estudiantes, de una manera $u$ otra han contribuido a propiciar cambios en las relaciones entre los actores escolares, como producto de redefiniciones y nuevas formas de percibir aspectos como la norma, la disciplina y la democracia.

El objetivo de esta reflexión es describir las concepciones y funcionamientos de estas tres categorías de análisis la democracia, la disciplina y las normas. El contexto en el cual se analizan dichas categorías es interesante, pues se trata de una coyuntura de crisis y transformación de la institución escolar, un momento en el cual la escuela ya no cumple el papel de institución integradora que difunde principios y valores que son aceptados sin cuestionamientos por los individuos, valores como la libertad y la autonomía, proclamados por la misma escuela, han provocado que los estudiantes, docentes y padres de familia acepten y acaten algunas disposiciones de las instituciones educativas, rechacen otras y reacomoden algunas a sus necesidades e intereses.

El diseño metodológico de la investigación de la cual se deriva el artículo combinó tres técnicas: la encuesta, la entrevista y el análisis documental. Se realizó una encuesta con un muestreo aleatorio simple a 250 estudiantes, hombres y mujeres de $6^{\circ}$ a $11^{\circ}$ grado (diez estudiantes de la lista de cada uno de los 25 grupos), a 20 docentes, doce mujeres y ocho hombres. La encuesta tuvo tres baterías de preguntas cerradas sobre normas, democracia y disciplina escolar. La sistematización y el análisis de los datos se realizó 
con el apoyo del programa Microsoft Excel, se construyó primero una tabla y posteriormente una gráfica estadística para cada una de las preguntas, sobre estos datos se hicieron las inferencias y las lecturas que constituyen parte de los resultados de la investigación.

Las entrevistas se hicieron con diez estudiantes, cinco docentes y dos directivos docentes, (una coordinadora y el rector), fueron utilizadas como fuentes de información clave para reconstruir las percepciones que tenían los diferentes actores escolares alrededor de la disciplina, la democracia y las normas en la institución escolar. Dichas entrevistas de dos o tres sesiones se hicieron fuera de la institución educativa, en lugares solicitados por los entrevistados. Tanto de las entrevistas como los relatos se hicieron transcripciones y, a partir de su lectura, se construyeron categorías analíticas que enriquecieron significativamente los hallazgos de la investigación.

Los documentos analizados fueron las actas de reuniones del colegio y el observador del alumno (la hoja de vida), documento en el que se registran, además de los datos personales, los asuntos relacionados con el rendimiento académico y el comportamiento de los estudiantes. También se incluyeron como fuentes primarias algunos documentos en los que hay huella de la política educativa del país, planes, decretos, e informes de gestión del Ministerio de Educación Nacional. La información de los documentos tuvo un tratamiento cualitativo y cuantitativo que complementó la información de la encuesta y las entrevistas.

Los estudiantes, docentes y padres de familia viven la transformación de la escuela como una crisis que cada uno enfrenta desde sus propias perspectivas. Los maestros sienten que su labor ha perdido reconocimiento y valor social y, en contraste con lo anterior, cada día tienen mayor cantidad de trabajo, que los fatiga y agota, sin recibir una justa remuneración; los estudiantes cuestionan la utilidad de los estudios, que ya no constituyen un factor de cohesión e integración de la vida escolar; los padres de familia añoran la escuela del pasado, recuerdan con nostalgia los tiempos en que sus hijos sí aprendían los contenidos de las asignaturas y a comportarse bien, tanto en la escuela como en la casa, e incluso en la calle.

Las críticas de los estudiantes y de los padres de familia se enfocan en cómo los métodos de enseñanza y las pedagogías utilizadas por los maestros no 
ayudan a un mejor desenvolvimiento en la vida en sociedad, situación que provoca en ambos la percepción de poca utilidad en la vida diaria de aquello que se enseña en la escuela. Según el informe final del Proyecto Atlántida, ${ }^{2}$ la utilidad que los jóvenes y sus padres perciben en la mayoría de los saberes, es la aprobación de exámenes para pasar de un grado a otro.

No hay integración de los aprendizajes de los adolescentes, con su experiencia personal, el contacto con la ciudad, con los grupos de pares porque la escuela tiene su propia manera de concebir el conocimiento y la realidad desde programas curriculares tradicionales, caracterizados por la secuencialidad, el formalismo y el simplismo en la definición de lo correcto y lo incorrecto.

\section{Disciplina, norma y democracia: tres variables insepa- rables en la escuela de hoy}

Un estudio sociológico sobre el funcionamiento de la disciplina, la norma y la democracia escolar hoy tiene que pasar obligatoriamente por una reflexión sobre aquello que la educación y la escuela se han planteado como meta y aquello que en la realidad puede ser observado en el comportamiento de hombres y mujeres que reciben educación, pues como decía Durkheim, cada sociedad educa a partir de cierto ideal de hombre, de lo que (en ella) se cree que este deber ser, tanto desde el punto de vista intelectual como físico y moral, ${ }^{3}$ pero en la cotidianidad de la escuela y en las relaciones entre sus actores no necesariamente se reproduce aquello que se ha planteado como deseable.

"La educación es concebida como el acceso universal a la ciencia y a la razón gracias a la existencia de una cultura racional objetiva, acumulativa, transmitida bajo la forma de un ethós del progreso"; 4 en el estudio "Educación la Agenda del Siglo XXI", la educación es definida como el vehículo principal e indiscutible para la transmisión de cultura, en el mismo trabajo Gómez plantea que:

2 El proyecto Atlántida fue dirigido por Francisco Cajiao y Rodrigo Parra Sandoval, tuvo como objetivo, indagar sobre la cultura adolescente escolar en Colombia. Fue una investigación financiada por la Fundación FES y Colciencias que contó con la participación de varias universidades del país. Publicado en 1995.

3 Emilio Durkheim. Educación y Sociología (Bogotá: Editorial Babel, 1976), 87.

4 Francois, Dubet y Danilo Martuccelli. En la Escuela. Sociología de la Experiencia Escolar (Buenos Aires: Editorial Losada, 1997), 20. 
[...] dos grandes funciones cumple la educación, una individual y otra social, la función individual cobija a su vez: la función de socializar, transmitir la cultura y desarrollar la personalidad (asociada con el papel de ciudadano adulto); la función de formar para el trabajo (asociada con el papel ocupacional), y la función de entrenar para la ciencia y la tecnología (asociada con los roles o papeles de la alta inteligencia). Las funciones "sociales" son de carácter mediato o indirecto, porque dependen de la circulación del saber y de la preparación de los individuos. Estas funciones se dan en un plano agregado y aluden a los grandes objetivos sociales que suelen atribuirse a la educación, esto es: la integración nacional, el crecimiento económico y la superación de la pobreza. ${ }^{5}$

Bajo este enfoque, la educación busca asegurar la estabilidad del orden social y la continuidad de la memoria colectiva.

En esta lógica del sistema escolar, el individuo es obligado a integrarse al adoptar un estatus de alumno o maestro, adhiriendo a las formas legítimas de la autoridad, ocupando un lugar y un rol preexistentes;

Ser alumno es comprender e interiorizar las expectativas de la organización, situarse en el orden de las jerarquias escolares; también es socializarse a través del juego de los grupos de pertenencia y de los grupos de referencia. Toda experiencia escolar es definida por esta lógica de la integración, por esta forma del aprendizaje de las normas propuestas, y ésta es la imagen más habitual de la socialización escolar percibida como el aprendizaje de roles sucesivos y como la transformación de la personalidad por esas transformaciones de roles. ${ }^{6}$

La educación así concebida asegura la integración del individuo a la sociedad por medio de una institución escolar que suscita en el niño un cierto número de estados físicos y mentales que se consideran necesarios e indispensables. Este modelo escolar se caracteriza por un sistema disciplinario bastante rígido, dirigido a controlar todas las conductas que podrían derivar en peleas, robos, y cualquier acción que perturbe el orden establecido, se trata de demostrar que la escuela es otro mundo, distinto al exterior por sus reglamentos.

5 Hernando Gómez Buendía. Educación la agenda del siglo XXI hacia un desarrollo humano. Programa de Naciones Unidas para el desarrollo (Bogotá: Tercer Mundo Editores, 1998), 105.

6 Francois Dubet y Danilo Martuccelli, "En la Escuela”, 20. 
Si bien en nuestras escuelas se cumplen algunas funciones de producción de conocimiento (muy criticadas especialmente por la falta de calidad) y también de socialización que crean lazos afectivos, algunas de ellas se caracterizan por disparidades y desacuerdos en la forma de pensar y de actuar entre sus miembros, alrededor de aspectos como el valor de los estudios, las formas de organización social que operan en estas, la disciplina y las normas que rigen en los establecimientos. En parte porque el tipo de relaciones que se dan en ellas permite diversidad de metas ${ }^{7} \mathrm{y}$ en parte porque su organización es producto de la naturaleza misma de la organización y además está determinada por presiones externas, las instituciones educativas contienen en su seno miembros que aspiran y tratan de alcanzar metas muy diferentes, pero por otro lado se enfrentan con todo un conjunto de exigencias y expectativas, a menudo contradictorias, de públicos y organismos externos.

Los estándares curriculares de ciencias sociales, creados por el Ministerio de Educación en el año 2003 y que cuentan con una estructura por grupos de grado desde primero de primaria hasta el último grado de la educación media, y que según el Ministerio deben ser el punto de partida de los planes de estudio de las instituciones educativas, hacen énfasis en la importancia en que los estudiantes se sientan parte de la sociedad y en que su acción como educando y luego como adulto vinculado a la vida laboral contribuya al mejoramiento de dicha sociedad. En uno de sus apartes, los estándares curriculares señalan que una de sus metas es aportar a la formación de hombres y mujeres miembros activos de una sociedad, puesto que el conocimiento científico nos permite reconocer la unidad, la diversidad y la interdependencia del mundo natural y social, una adecuada formación en ciencias sociales fomenta el respeto por la condición humana y la naturaleza, que se traduce en una capacidad para tomar decisiones en todos los ámbitos de la vida, teniendo presente sus implicaciones en cada uno de los seres que habitamos el planeta: niños, niñas, jóvenes, hombres y mujeres, adultos, ancianos y ancianas, poblaciones de diversas etnias y de condiciones socio-culturales diferentes, animales, plantas, recursos hídricos y minerales, en fin, en ese gran conjunto que hemos llamado la Tierra y que los seres humanos hemos ayudado a configurar. De igual manera, comprender quiénes somos, cómo nos hemos constituido

7 . Stephen Ball, La micro política de la escuela hacia una teoría de la organización escolar (Barcelona: Editorial Paidós, 1989 ), 53. 
en seres humanos, qué caminos hemos recorrido, qué nos caracteriza, qué sentido le damos a nuestra presencia en la Tierra, cómo nos organizamos socialmente, qué concepciones ideológicas nos orientan, cuál es nuestro papel en el desarrollo del mundo futuro, elementos que nos proporciona el conocimiento científico, nos permite a los seres humanos ubicarnos en un momento histórico determinado y en un contexto cultural, político e ideológico, todo lo cual orienta nuestras acciones. ${ }^{8}$

De otro lado, este trabajo plantea, a manera de idea exploratoria, que algunos estudios realizados en las décadas del ochenta y noventa sobre la vida escolar en Colombia y más concretamente sobre el poder, la justicia, el castigo y las normas escolares, así como la utilización de herramientas jurídicas como nuevas leyes, decretos y la tutela consagrada en la constitución política de 1991- pudieron tener una influencia relativa en algunos cambios en la dimensión jurídica (normativa) de la educación del país; que a su vez han provocado pequeños cambios de las relaciones entre los actores escolares, producto de redefiniciones y nuevas concepciones sobre aspectos como la norma, la autoridad y la disciplina. Dichos trabajos respondieron a interrogantes como ¿Qué relaciones se dan entre los actores escolares? ¿Cuál es el sentido que le dan dichos actores a sus relaciones? ¿Qué sucede en la escuela? ¿Cómo se enseña y cómo se aprende? ¿Por qué se fracasa y por qué se aprueba? Estas investigaciones fueron impulsadas por instituciones como la fundación FES, diversas universidades, especialmente el Centro de Investigaciones de la Universidad Pedagógica Nacional CIUP, pero también investigadores individuales y en grupo como el caso de la obra de Francisco Cajiao, Parra Sandoval y sus equipos de investigación.

También se señala que algunos cambios en la legislación educativa han sido acogidos en la escuela, más por el camino de la exigencia y de la obligatoriedad que por un cambio de mentalidad que permita considerar dichos cambios como útiles y necesarios, pero se quiere resaltar que pese a la resistencia de algunos docentes y directivos, sí se pueden evidenciar ya pequeños cambios en la escuela, principalmente en lo relacionado con una relación más horizontal y abierta entre sus miembros y la apertura a ciertos espacios de discusión y concertación de temas de la vida escolar

8 Ministerio de Educación Nacional. Estándares básicos de competencias en ciencias naturales y en ciencias sociales. (Santa Fe de Bogotá: Ministerio de Educación Nacional, 2003), 6. 
sobre los que antes no había ni discusión ni concertación, es decir, hay ya instituciones educativas donde se han presentado por parte de maestros, padres de familia, directivos y estudiantes esfuerzos por construir espacios más participativos y se han introducido tímidamente principios como la libertad y la autonomía.

La necesidad de cambios en la normatividad educativa del país, en lo relacionado a la organización social de las instituciones y al tipo de relaciones que se dan entre sus miembros, surge del ambiente conflictivo de la escuela en dos ámbitos; el macropolítico (relación de la escuela con el Estado, la sociedad civil, la Iglesia, las metas de las políticas educativas, etc.) y el micropolítico (relaciones entre los miembros de la comunidad educativa). ${ }^{9}$ El propósito fue el de responder a la necesidad de disminuir las diversas expresiones de violencia escolar generadas como consecuencia de la intolerancia, la injusticia social, la pérdida de valores, la violación de los derechos humanos, que se vivía en las instituciones educativas, según algunos trabajos como “¿Cumplen los castigos una función educativa?”, “Alumnos problema o maestros problema?", “Timidez y agresividad en la escuela”, “La autocracia escolar", “La fuga de la ilusión”, “¿Es fácil la comunicación con los niños?”, "Poder y justicia en la escuela colombiana".

La principal conclusión de dichos trabajos fue que en Colombia la institución escolar permaneció inmodificada desde la definición de sus lineamientos generales en el siglo XIX, debido a su aislamiento del medio exterior, aunque existían cambios en los contenidos impartidos, de acuerdo con las demandas de la dinámica social. También se concluyó que la escuela siguió teniendo los mismos rasgos autoritarios, represivos y de vigilancia y control con los que inició el siglo, entre los que se destacan la autoridad incuestionable como característica definitoria del rol del maestro, el dogmatismo como manifestación de la autoridad en el terreno pedagógico, la disciplina como uno de los pilares del funcionamiento de la institución educativa, y como instrumento para garantizar la homogeneización y la normalización, el cuerpo como el principal objeto de control, la definición estricta de espacios, tiempos y funciones, la administración arbitraria de justicia, y una legislación propia que funciona al margen del estado social

9 Xesús, Jares "El lugar del conflicto en la organización escolar". Revista Iberoamericana de educación 15 (1997): 35-40. 
de derecho. En este panorama, la escuela colombiana fue caracterizada por la subordinación de sus funciones (académicas y de socialización) a las de disciplina y control, lo que generó un ambiente en el cual la democracia no tenía cabida. ${ }^{10}$

La verticalidad y la falta de flexibilidad en las relaciones sociales de la escuela en el siglo XIX lógicamente afectaron los diseños curriculares de ciencias sociales, en la medida en que los discursos y las prácticas pedagógicas de los maestros estaban lejos de brindar bases que les permitieran a los y las estudiantes acercarse paulatinamente y de manera rigurosa al conocimiento y a la actividad del científico social, a partir de la indagación, lo que permitió alcanzar comprensiones cada vez más complejas, todo ello por medio de lo que se denomina un hacer. Dicho de otra manera, la concepción y el funcionamiento de aspectos como la disciplina y el poder en la escuela dificultaban transformaciones profundas en los diseños curriculares y en las prácticas de los educadores, porque para lograr esto se requiere de un papel activo por parte del estudiante, se requiere de un docente que enfoque su enseñanza de manera diferente, en donde su papel no se limite a la transmisión de conocimientos o demostración de experiencias sino que oriente el proceso de enseñanza y aprendizaje de sus estudiantes como un acompañante.

La solución a la problemática antes descrita de autoritarismo y abuso del poder, verticalidad en las relaciones sociales, escasa participación de actores escolares como estudiantes y padres, falta de mecanismos en la aplicación de la justicia, es, para los planificadores de la educación, "la democratización de la vida escolar". La extensión de la democracia en la escuela ha sido un proyecto tendiente a dar a esta un nuevo enfoque en su cultura política, un enfoque democrático. ${ }^{11}$ Para lograr el objetivo de democratizar la vida escolar, en el caso colombiano, se han tenido en cuenta tres dimensiones: la dimensión cognitiva, (conocimientos y creencias de los sujetos en un modelo político democrático), la afectiva (sentimientos en torno a los componentes de un modelo democrático: aceptación o rechazo) y la dimensión evaluativa (valoración que los sujetos hacen sobre el funcionamiento de la democracia). La tendencia a formar desde la cultura política no es nueva, la idea del papel

10 Francisco Cajiao. Poder y Justicia en la Escuela Colombiana. Vida Escolar en Colombia. (Bogotá: Fundación FES, 1994), 87.

11 Fabio de la Roche. La Construcción de la Cultura Política en Colombia. Universidad Pedagógica Nacional. (Bogotá: Universidad Pedagógica Nacional, 2005), 27. 
del sistema de enseñanza pública como garante de la formación ciudadana y por medio de el posibilitar la difusión y apropiación del ideario de estado está presente desde Durkheim, para quien la educación debe ser la base de las sociedades, en la medida en que ella dota a los individuos de los códigos necesarios para constituirse como ciudadanos autónomos. ${ }^{12}$

Dentro de esta perspectiva, el objetivo de democratizar la escuela ha apuntado no solo a regular las relaciones en los establecimientos sino también a educar a los estudiantes para que cuando sean ciudadanos participen de los mecanismos diseñados por el sistema político, de allí la importancia de la enseñanza de valores cívicos, como el respeto y el acatamiento a las normas que fortalecen la democracia. La formación ciudadana es vista como un proceso de instrucción-socialización de los sujetos en un modelo específico de cultura política, en este caso el democrático. Lo que aquí se plantea es que en el país, en las dos últimas décadas, se han producido cambios tendientes a transformar la organización social de los establecimientos educativos, pero dichos cambios se han pretendido hacer a partir del concepto cultura democrática, ámbito en el cual la escuela se entiende como una institución social que produce sus propias dinámicas que se expresan en sus formas de ser y hacer, en sus símbolos y rituales, normas y valores en los roles y funciones que se otorgan a los actores educativos y las formas de organización del poder. ${ }^{13}$ En este orden de ideas, el concepto de cultura democrática en la escuela representa una forma particular de expresión de dicha cultura escolar. Sobre dicha categoría Aguilar y Betancourt, plantean que:

el concepto de cultura democrática en la escuela se entiende como el complejo de significados que estructuran los comportamientos, las prácticas, los deberes, valores y representaciones que configuran el marco de las relaciones de convivencia en el ámbito escolar, los cuales están basados en principios democráticos, aspectos que le confieren un sentido particular a este tipo de convivencia. ${ }^{14}$

La necesidad de la democratización de la escuela colombiana es un proyecto en el que en él variados actores, como también variados intereses y un momento histórico determinado. En este capítulo nos referimos a tres,

12 Emilio Durkheim. La Educación Moral. (Buenos Aires: Editorial Shapire, 1992), 85.

13 Ministerio de Educación Nacional. Reforma Educativa y Proyecto Educativo Nacional. Reinvención de la Institución Escolar. Informe al Congreso Nacional. 1994 -1998. (Bogotá: Ministerio de Educación Nacional, 1998), 15.

14 Juan Francisco Aguilar y José Javier Betancourt. Construcción de una Cultura Democrática en Instituciones Educativas de Bogotá. (Bogotá: IDEP, INNOVE, 2002), 39. 
el contexto internacional, el contexto nacional y los actores escolares. En el contexto internacional hay que destacar que el país no se encuentra aislado ni física ni culturalmente, por ello hay que destacar que en la implementación y puesta en funcionamiento de proyectos como el democratizar la escuela, también tienen influencia organismos internacionales, más aún si tenemos en cuenta que no pocos proyectos de este tipo en países como el nuestro son financiados con sus recursos económicos y con la asesoría de sus expertos. ${ }^{15}$ Las reformas educativas de los años noventa en toda América Latina estuvieron inscritas de alguna forma en las sugerencias y recomendaciones de las políticas internacionales, en el caso de la "democratización de la vida escolar" no es rara esa influencia si tenemos en cuenta que en las dos últimas décadas del siglo XX el ideal de la democracia fue un referente obligado en toda la región.

En el ámbito nacional, hay que destacar que, en el ambiente político y cultural que vivió Colombia a partir de la década de los noventa, marcado por la emergencia de cambios en materia constitucional, la educación se vio comprometida con la formación de ciudadanos y, en general, con la construcción de una cultura política democrática. La Constitución colombiana de 1991 consagró la educación como un servicio público y otorgó al Estado la responsabilidad de ejercer su inspección y vigilancia con el fin de velar por su calidad, por el cumplimiento de sus fines y la mejor formación moral, intelectual y física de los educandos. El reconocimiento de la educación como un servicio público en la nueva constitución permitió al estado reclamar para sí la reglamentación y control sobre esta y demandar de todas las instituciones los mismos requerimientos para fortalecer la construcción de una cultura política democrática basada en la defensa de los derechos humanos y la formación para la paz. Desde este punto de vista, las disposiciones normativas en torno a la educación y sus propósitos de contribuir a la construcción de cultura política democrática cumplen un papel de legitimación institucional en momentos de profunda crisis social y política. ${ }^{16}$

También hay que resaltar que la necesidad de lograr una cultura democrática en la escuela es planteada por los estudiantes y por los padres de familia,

15 Graciela Frigerio et al. Políticas Institucionales y Actores en Educación. Centro de Estudios Multidisciplinarios. Colección Reflexión y Debate. (Buenos Aires: Ediciones Novedades Educativas, 1997), 21.

16 Humberto Cubides “Gobierno Escolar: Cultura y Conflicto Político en la Escuela". Revista Nómadas 15 (2001): 17-28. 
quienes intervienen en la transformación y construcción de las instituciones de las cuales hacen parte, es por ello que en procesos como el que se ha denominado la democratización de la vida escolar, también ha cumplido papel muy importante el carácter creador de la acción humana, para este caso, de los actores escolares, tanto de los docentes como de los mismos estudiantes, que desde sus acciones, tanto individuales como colectivas, están buscando cambios en la organización social de las instituciones y ya han logrado algunos, por lo menos en lo concerniente a la entrada y a la apropiación de los nuevos discursos. ${ }^{17}$

El propósito de la democratización también está claramente definido en el informe que da el Ministerio de Educación al Congreso, de la gestión realizada entre 1994 y 1998. Se plantea en dicho informe que durante los cuatro años del gobierno Samper, el Ministerio intensificó una labor orientada a democratizar las estructuras de poder en los establecimientos educativos y la construcción de relaciones de convivencia, respeto y pluralidad, labor que se lograría por medio de la formación de los gobiernos escolares, de personeros estudiantiles y de manuales de convivencia. El camino legal hacia la democratización queda más abiertamente planteado en el plan decenal de educación 1996-2005.

Se trata de poner en vigencia los mecanismos de participación de los alumnos, los educadores y la comunidad en el gobierno escolar (consejo directivo, consejo académico y personeros); promover las organizaciones de padres, alumnos y exalumnos; establecer espacios de diálogo y concertación para los diferentes miembros de la comunidad educativa. ${ }^{18}$

Dicho plan además contempló el objetivo de la democratización y las metas para alcanzarla, el objetivo era lograr que la educación sirviera para el establecimiento de la democracia, el fomento de la participación ciudadana y la construcción de la convivencia pacífica, las metas eran construir en las instituciones educativas los espacios de debate, participación y concertación para todos los miembros de la comunidad educativa, ampliando y perfeccionando los mecanismos establecidos en la Ley General de Educación; propiciar la creación de manuales de convivencia, creados colectivamente a partir de la práctica y la reflexión sobre el ejercicio del gobierno escolar y la

17 Graciela Frigerio et al. Políticas Institucionales y Actores en Educación, 30

18 Ministerio de Educación Nacional. Reforma. Plan Decenal de Educación 1996-2005. (Bogotá: Ministerio de Educación Nacional, 2006), 15. 
solución de conflictos y promover la enseñanza y el estudio sistemático de la Constitución Política y fomentar los principios y valores de la participación ciudadana.

Estos cambios en la ley se dan a partir de planteamientos según los cuales "la democratización permitiría una nueva concepción en las relaciones entre maestros y estudiantes, ámbito en el cual la disciplina adquiere un sentido formativo, al dejar de lado su aspecto represivo, instituyendo en la organización escolar un verdadero sistema de justicia en el que se oye al estudiante y este tiene derecho a la defensa. Algunos proyectos y programas se han desarrollado en varios departamentos del país bajo el impulso del Ministerio y de las Secretarías de educación, para señalar solo algunos: el Proyecto de investigación y desarrollo Jóvenes constructores de paz; Proyecto escuelas básicas integrales para el desarrollo sostenible; Escuela de derechos humanos, paz y convivencia; Hacia la construcción de una cultura ciudadana; Programa para la gestión del conflicto escolar; Programa inteligencia emocional; Programación de formación permanente en convivencia paz y no violencia; Escuelas de liderazgo político. ${ }^{19}$ La aplicación de estos programas apunta a una reestructuración de la organización escolar que permita la participación de todos los implicados en los diversos ámbitos que componen la institución, en este contexto la participación adquiere un carácter diferente, pues, además de ser el eje fundamental del ejercicio ciudadano, se constituye en un medio para el desarrollo de procesos propios de la formación, como el desarrollo de la personalidad dentro de una cultura democrática.

Para subrayar lo planteado en el párrafo anterior, es preciso describir algunos de los proyectos que se han ejecutado, el Proyecto de investigación y desarrollo jóvenes constructores de paz empezó en 1998, funciona en 21 instituciones educativas de Manizales, Pereira y Armenia, nueve instituciones de Manizales 58 escuelas y colegios del Huila y ocho escuelas de Bogotá. Partió del reconocimiento a las múltiples y variadas formas de violencia que han ido creciendo progresivamente en los distintos escenarios de construcción humana en Colombia, y del análisis crítico sobre cómo las distintas alternativas de educación para la paz desarrolladas en el país no han tenido en cuenta la voz de los niños, las niñas, los jóvenes: ¿qué piensan?, ¿cuáles son sus imaginarios sobre la violencia, sobre la paz?, ¿cómo viven y

19 Ministerio de Educación Nacional. Reforma Programas estructurados nacionales para el desarrollo de las competencias ciudadanas (Bogotá: Ministerio de Educación Nacional, 2003), 17 
sienten el contexto de violencia que les está tocando vivir?, ¿cómo sueñan su país?, ¿cómo creen que se pueden ir construyendo y realizando sus sueños? Así, se trazó como objetivo del proyecto construir una propuesta educativa para la paz, pensada, diseñada e implementada por los propios niños y niñas vinculados al programa, para lograr un mayor impacto en la vida de ellos y ellas, y encontrar estrategias educativas para la paz que pudieran diseminarse ampliamente en el ámbito nacional.

Programa para la gestión del conflicto escolar "Hermes", es un proyecto implementado desde 2001 por la Cámara de Comercio de Bogotá con el objetivo de fomentar el diálogo y la tolerancia en la comunidad, es una apuesta colectiva al cambio social, desde núcleos primarios como la escuela, con una incidencia significativa en las dinámicas familiares, sociales y culturales. El proyecto pretende una transformación cultural para abordar el conflicto pacíficamente, teniendo en cuenta el papel fundamental que cumple la educación. La conformación de los órganos creados por la ley para garantizar la participación de todos los estamentos de las instituciones educativas y los derechos que han sido concedidos a los estudiantes dentro de estas se desarrollan simultáneamente con el surgimiento y multiplicación de actitudes y comportamientos que alteran el orden y normal desarrollo de las actividades escolares, y que son catalogadas como "indisciplina". De esta manera, el escenario de la democratización ha coincidido con situaciones de falta de armonía entre los docentes y los estudiantes, el problema disciplinario se ha agudizado y en algunos establecimientos se constituye en el principal centro de preocupación, dejando en un segundo plano aspectos como la calidad académica de los estudiantes.

Uno de los hechos que ha provocado la emergencia del tema de la "disciplina" es el cambio de visión que sobre este aspecto tenían los estudiantes y docentes en la escuela de ayer, la disciplina era en sí misma un factor de educación por medio del cual el estudiante moderaba todos sus comportamientos. Las normas que regían las instituciones y que definían los criterios disciplinarios eran creados de manera unilateral por los docentes y normalmente los estudiantes los aceptaban, hoy los criterios disciplinarios ni son aceptados en sí como una disposición institucional, ni se comparte el hecho que sean creados unilateralmente, dichos criterios deben pasar por un proceso de concertación y debate, de lo contrario son considerados por los estudiantes como ilegítimos y por ello suelen tener poca aceptación. 
En la manera como se concebía la necesidad de la disciplina, se nota una gran diferencia en la forma como eran considerados en el pasado los niños y adolescentes y la manera como se les considera hoy, estos eran considerados como carentes de sentimientos y conocimientos de la existencia de límites morales a sus necesidades; la disciplina era por lo tanto aquello que garantizaba las fuerzas contra las cuales se estrellan los deseos, las necesidades y los apetitos, aquella que contenía todo lo necesario para doblegar las voluntades de los estudiantes, reprimirlos, contenerlos e inclinarlos hacia determinado sentido, en consecuencia la disciplina era indispensable para detener y contener las fuerzas rebeldes. ${ }^{20}$ La consecución de este modelo de disciplina requería la presencia de maestros que hicieran sentir a los estudiantes que encarnaban y representaban las reglas de la institución y que las hacían respetables, para esto era necesario la decisión y la voluntad del maestro, así como la autoridad que en todo momento debería transmitir.

Hoy la autoridad escolar choca con los reclamos de los estudiantes por ejercer su libertad y autonomía, ante lo cual los docentes a menudo se perciben como empleados a quienes se les quita progresivamente el apoyo de la sociedad, el mismo "oficio" se vuelve cada vez más difícil y estresante porque los alumnos ya no son conquistados, dado que la escuela no puede desprenderse de los estudiantes que le causan problemas con la misma facilidad con que lo hacía en otros tiempos, los docentes tienen la impresión de convertirse en empleados cuyos derechos son ignorados.

En efecto, los conflictos disciplinarios alternan con el surgimiento de nuevos valores y principios que se promovían en la escuela, y coinciden principalmente con transformaciones en las concepciones de los estudiantes, producto de cambios en el proceso de formación de la identidad individual, dicho proceso lleva a los jóvenes estudiantes a buscar su reconocimiento como personas, determinadas y únicas, en una experiencia que solo se da en relación con los demás y que determina el mutuo reconocimiento, pero que también lo lleva a una fuerte etapa de construcción de autonomía y autorregulación que entra en conflicto con las ya instauradas reglas de los adultos. ${ }^{21}$ En la formación de la identidad, los jóvenes estudiantes hacen fuertes cuestionamientos a las generaciones anteriores, a las instituciones

20 Emilio Durkheim. La Educación Moral (Buenos Aires: Editorial Shapire, 1992), 86.

21 Ana Lucía Paz. Conflicto en la Escuela, configuración de Espacios de Mediación. (Santiago de Cali: Alcaldía Municipal Universidad del Valle, 2005), 65. 
educativas y a sus modelos de socialización; el conflicto se presenta cuando los adultos no comparten las reivindicaciones de los estudiantes e incluso las reciben como agresiones frente a las cuales se defienden con la imposición de unas normas que no siempre son compartidas sino más bien rechazados por los jóvenes, de allí que las causas de conflicto más frecuentes en los colegios se presentan por desobediencia, rebeldía y apatía de los estudiantes hacia las normas escolares.

En este sentido, hay que decir que cuando la disciplina y las normas como elementos centrales de la cultura institucional aparecen notoriamente fragmentadas, cuando conviven en la escuela de manera conflictiva diversas concepciones y diversas prácticas disciplinarias, cuando el sentido y utilidad de las normas se perciben de manera distinta se genera una tensión en maestros y alumnos, lo que provoca que estas normas pierdan su valor como elementos de formación, pero también hay que decir que en el caso de la escuela colombiana todo este proceso de surgimiento de nuevas ideologías y nuevas formas de actuar solo se entiende dentro de un proceso mayor de transformación de la institucionalidad misma de la escuela, transformación que en muchos establecimientos educativos se ha vivido como una crisis, como una entrada en decadencia, como una desestabilización de los principios, y los objetivos de la institución escolar.

Estas reformas hacen parte del intento por introducir al país lo que se llamó la tecnología educativa, acciones programáticas tendientes a la organización de un sistema permanente de información y capacitación con énfasis en la difusión de las nuevas tecnologías; algunas escuelas del país fueron dotadas de modernos equipos para la enseñanza y un grupo de profesores y técnicos expertos en el manejo de medios, como parte de un experimento arquitectónico articulado a los nuevos derroteros de la pedagogía y las directrices nacionales, que partían de la crítica a los espacios tradicionales y que privilegiaban la introducción de una nueva metodología centrada en la aplicación de aquellas técnicas que buscaban acelerar el proceso de enseñanza-aprendizaje en el alumno, al desarrollar al máximo su actividad, racionalizando los costos y cumpliendo las exigencias de cobertura y calidad. La innovación estaba compuesta por el análisis la tecnología educativa, el desarrollo de un modelo de análisis de sistemas aplicado al diseño de materiales de instrucción y una presentación de las ventajas enfrentadas a los problemas diarios de la práctica educativa. Sin embargo, muchos de 
los proyectos y acciones que se tramitaron en la comunidad académica, relacionados con los procesos de introducción y transferencia de tecnología educativa en la educación básica y media, tanto en la utilización de medios como en la experimentación del nuevo modelo curricular, tuvieron desarrollos desiguales ${ }^{22}$ por factores de diversa índole, desde falta de presupuesto para el mantenimiento de los nuevos recursos físicos, y la falta de interés muchos docentes de vincularse a los programas hasta la falta de un procedimiento claro establecido por el Ministerio de Educación para hacer evaluación, seguimiento y control del nuevo programa. A lo anteriormente descrito sobre los cambios en la institución escolar hay que agregarle un elemento importante, el de la masificación escolar, porque la dificultad para describir el funcionamiento real de la escuela y el hecho de que esta ya no funcione como una institución integrada se debe en parte a este proceso. ${ }^{23}$ No se pueden entender los grandes cambios que ha sufrido la escuela hoy sin contemplar su apertura a públicos cada vez más diversos y en mayores cantidades. "La masificación escolar", es un aspecto fundamental, por cuanto ha cambiado las reglas del juego escolar, sus regulaciones, las relaciones pedagógicas y los vínculos de la escuela con el mundo exterior. Esta masificación está asociada con una idea democrática de reducción de las desigualdades sociales en el ámbito de la escolaridad, en el cual cumple un papel importante el crecimiento económico y la modernización del aparato productivo. En este sentido la escuela está hoy sometida a una finalidad de adaptación a la economía y a los empleos que se manifiesta especialmente en la creación continua de nuevas formaciones. ${ }^{24}$

La apertura de la escuela a una mayor cantidad de públicos ha provocado una fuerte diversificación de redes y de ofertas, en la medida en que las finalidades educativas son múltiples, en este proceso la organización pedagógica se ha desestabilizado. La personalidad de los actores escolares es sacudida por diversos elementos: el funcionamiento de la escuela como un mercado, el desajuste creciente entre las expectativas de los alumnos y de los profesores, la incertidumbre del derrumbe cultural de la escuela

22 Jorge Orlando Castro. Apuntes sobre la extensión de la tecnología educativa y el modelo curricular en el Distrito. Historia de la Educación en Bogotá, Alcaldía Mayor de Bogotá, Instituto para la Investigación Educativa y el Desarrollo Pedagógico -IDEP(Bogotá: Panamericana Formas e Impresos, 2002), 196 - 221.

23 Francois, Dubet, y Danilo Martuccelli, "En la Escuela”, 35.

24 Xesús Jares "El lugar del Conflicto en la Organización Escolar", 35- 40. 
misma, en este ámbito solo algunos maestros, estudiantes y directivos están verdaderamente conectados con la escuela, otros son aplastados por su misma dinámica. "La estandarización del proceso educacional se convierte en la base de su progresiva extensión a todos, así como la organización de la producción en las fábricas permite masificar los productos industriales" ${ }^{25} \mathrm{La}$ masificación de la escuela debía contribuir, adicionalmente, a la construcción de la Nación, tarea que se encomienda a la educación. Sobre estos aspectos se consultaron algunos datos del país, del departamento del Valle del Cauca y de la institución educativa en la cual se realiza el trabajo de investigación, los siguientes cuadros ilustran el aumento de la cantidad de estudiantes en primaria y bachillerato en el país en el siglo XX.

\section{Gráfico 1. Alumnos Matriculados en Primaria 1903-2000}

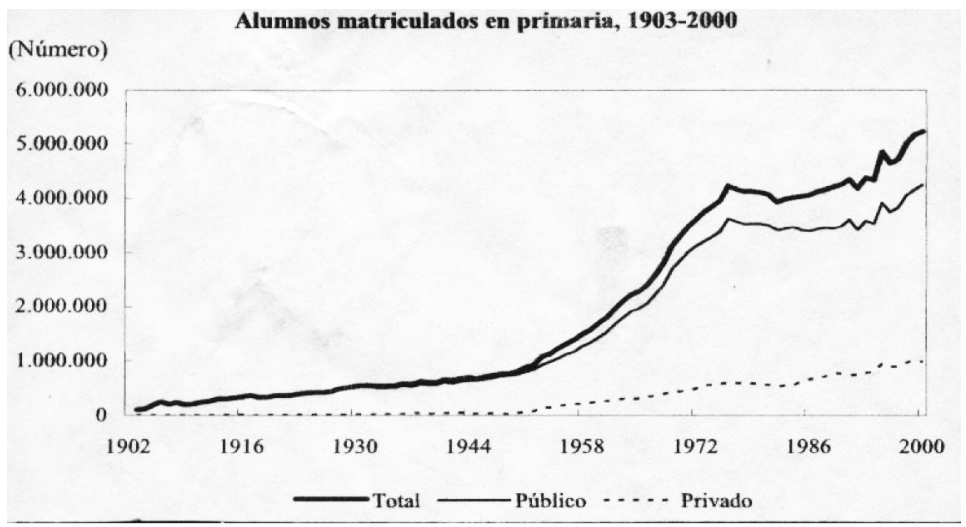

Fuente: MEN, Anuario General de Estadística y DANE.

En: La educación primaria y secundaria en Colombia en el siglo XX

Lo que muestran las cifras $^{26}$ para el caso de la educación primaría es un incremento realmente significativo en la cantidad de estudiantes matriculados, de menos de un millón matriculados en los años treinta a más de cinco millones finalizando el siglo, destacando además que los mayores crecimientos se producen entre 1970 y el año 2000, con un leve decrecimiento en la década del ochenta.

25 José Joaquín Bunner. Educación e Internet. ¿La próxima revolución? (Santiago de Chile: Fondo de Cultura Económica 2003), 45.

26 María Teresa Ramírez y Juana Patricia Tellez. La educación primaria y secundaria en Colombia en el siglo XX. (Bogotá: Unidad de Investigaciones de la Gerencia Técnica del Banco de la República, 2006). 


\section{Gráfico 2. Alumnos Matriculados en Secundaria 1903-2000}

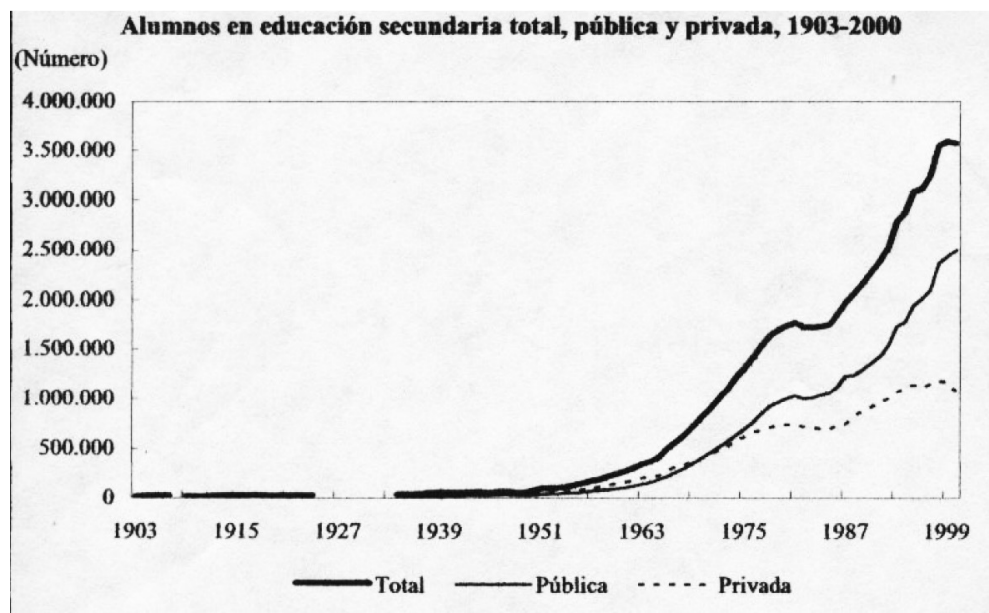

Fuente: MEN, Anuario General de Estadística y DANE.

En: La educación primaria y secundaria en Colombia en el siglo XX

En cuanto a la educación secundaria, si bien la cantidad de matriculados es inferior a la de primaría, también es notorio el aumento de aproximadamente quinientos mil estudiantes matriculados en 1963, se pasa a más de tres millones y medio al finalizar los años noventa, destacando que en esta etapa de educación es más importante la participación del sector privado que en la etapa de educación primaría. En los primeros años del presente siglo continúa siendo significativo el aumento de estudiantes, más aún si tenemos en cuenta que la ampliación de la cobertura escolar se ha vuelto una de las metas de los últimos gobiernos del país. 


\section{Grafico3: Asistencia escolar total en Colombia de 1992 al 2003}

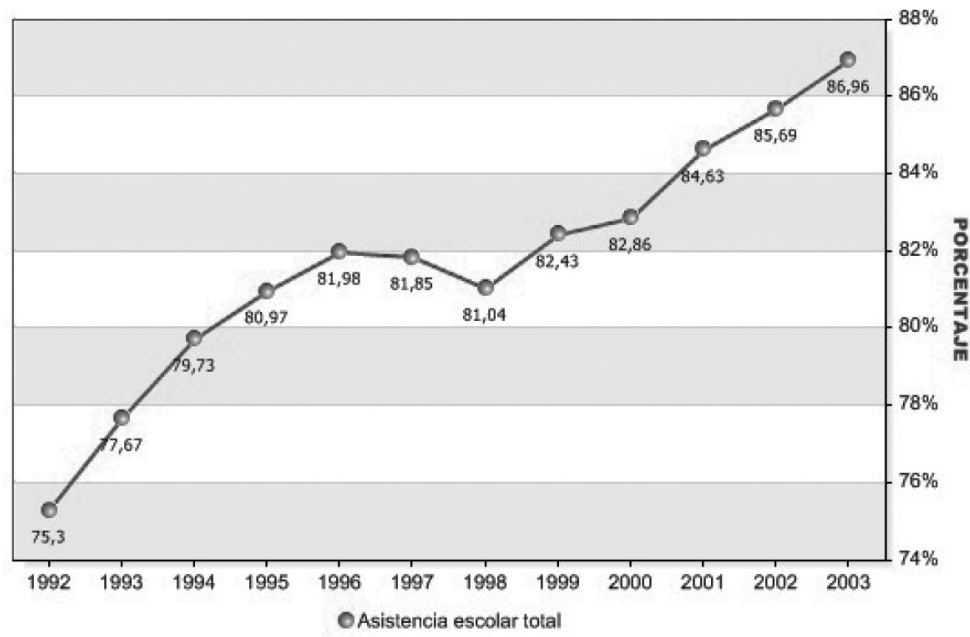

Fuente: Departamento Nacional de Planeación.

Dirección de Desarrollo Social. Página de Internet www.dnp.gov.co.

Tabla 1. Cobertura de Educación del País 2001-2005

\begin{tabular}{|c|c|c|c|c|c|}
\hline Año & $\mathbf{2 0 0 1}$ & $\mathbf{2 0 0 2}$ & $\mathbf{2 0 0 3}$ & $\mathbf{2 0 0 4}$ & $\mathbf{2 0 0 5}$ \\
\hline $\begin{array}{c}\text { Estudiantes } \\
\text { matriculados }\end{array}$ & 9576348 & 9994402 & 10323582 & 10501959 & 10785469 \\
\hline Cobertura & $79 \%$ & $82 \%$ & $84 \%$ & $85 \%$ & $88 \%$ \\
\hline
\end{tabular}

Fuente: Tomado de la página del Ministerio de Educación 


\section{Gráfico 4. Cobertura Nacional de Educación Básica y Media 2001-2005}

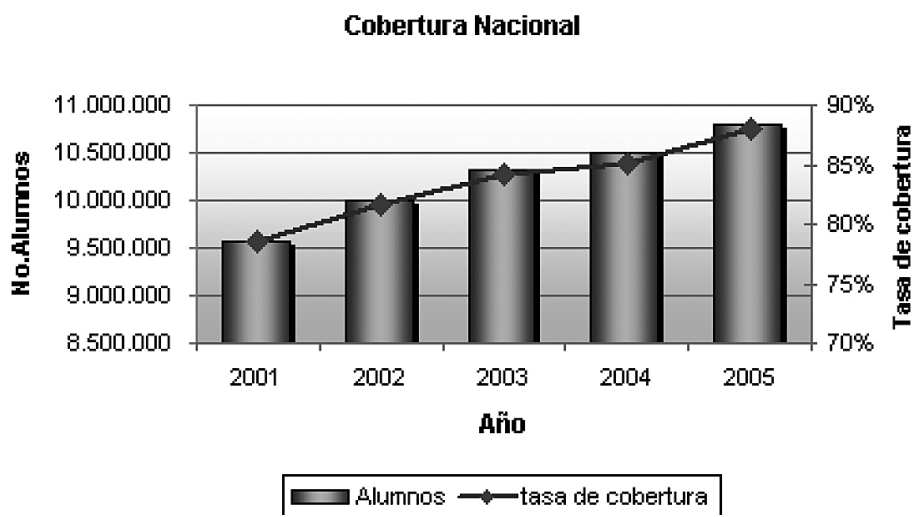

Fuente: Cifras de cobertura Ministerio de Educación Nacional 2001 - 2005. www.mineducacion.gov.co

\section{Gráfico 5. Matricula Total de Educación Básica y Media 2001-2005}

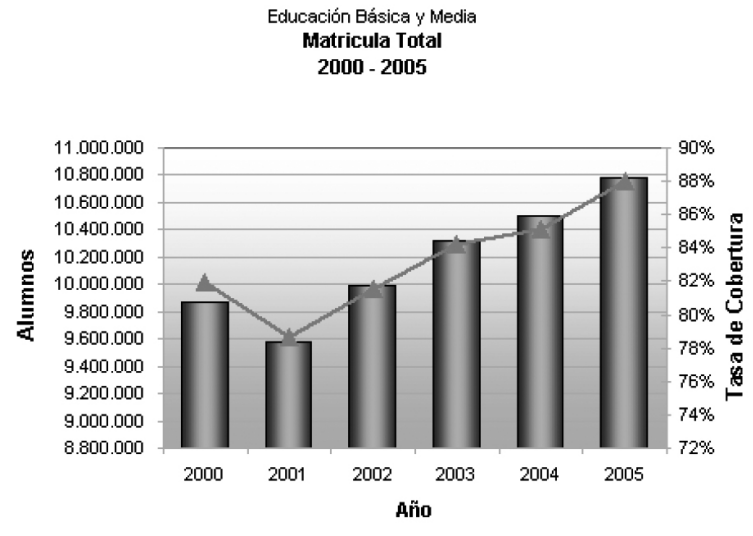

Fuente: MEN - Análisis Oficina de Planeación y Finanzas

Matricula $\longrightarrow$ Tasa de cobertura

La tabla y los gráficos anteriores en los que se muestra el comportamiento de la asistencia escolar, a partir de la década de 1990, permiten decir, para el caso colombiano, que hay un aumento considerable en el número de estudiantes matriculados en los grados de educación básica y media, así como un aumento significativo en la tasa de cobertura escolar. Las estadísticas del Ministerio de Educación muestran que en el año 2005 casi once millones de estudiantes asistieron a los grados de básica primaria, secundaria y media. La cobertura de educación básica llegó al 88\%. Según la información reportada 
por las secretarías de educación, 8310165 estudiantes fueron atendidos en establecimientos oficiales y 2475304 por establecimientos no oficiales. En cuanto a los establecimientos se contabilizaron 15723 instituciones educativas oficiales y 10812 no oficiales, estos datos dan fortaleza al argumento de una cuantiosa expansión en el número de niños y jóvenes que asisten hoy al sistema educativo colombiano.

No solo los niños y jóvenes que se escolarizan son más, sino que son diferentes, han ingresado al sistema escolar los hijos de otros grupos sociales que antes no asistían a la escuela, los jóvenes y los adolescentes de hoy son distintos de los primeros "usuarios" de la educación, debido a los grandes cambios en los modos de producción y en la estructura social y familiar.

\begin{abstract}
Las instituciones, en tanto que sistemas de reglas y recursos que estructuran las prácticas sociales y educativas, cambian de forma y significado. Los viejos dispositivos que regulaban la relación profesor-alumno, la relación con el conocimiento, garantizaban la autoridad pedagógica y producian un orden institucional, se erosionan. ${ }^{27}$
\end{abstract}

La masificación produce una serie de transformaciones en las instituciones escolares, como ya se ha señalado, la vieja escuela reservada a algunos grupos sociales hoy responde a la demanda de nuevos y cada día más miembros. Pero si bien la ampliación de la cobertura en educación ha traído beneficios como la disminución del analfabetismo y mayor cualificación de la fuerza laboral del país, en el día a día de las instituciones el aumento de los estudiantes y los cambios que anteriormente se nombraron, también se han traducido en hechos que han llevado a pensar que la escuela pasa por un período de crisis.

\title{
2. Cuando los cambios se viven como una crisis
}

Las transformaciones que ha tenido el mundo escolar son vividas por sus actuales actores como una profunda crisis, si bien los sentimientos, satisfacciones y aspiraciones del profesorado son de crucial importancia para comprender los logros de la escuela, los docentes han recibido las más fuertes de las críticas del sistema educativo. En los medios de comunicación,

27 Emilio Tenti Fanfani. Culturas juveniles y cultura escolar. Sobre escuela y juventud. (Brasilia: Ministerio de educación del Brasil, 2000), 10-18 
en la calle, entre los profesores universitarios y en la misma escuela se describe a los profesores de la educación básica y media como personas despreocupadas, mal preparadas, reacios al cambio, perezosos en el trabajo, en otras palabras, la figura del maestro se ha degradado, han perdido la imagen de respeto y admiración que tenían en el pasado, lo que conlleva a una reconstrucción de la relaciones de los profesores con su trabajo y su auto imagen de trabajadores.

\title{
[...] los profesores se acomodan mal al presente porque no se deshacen de una representación acabada y total de su rol, de la imagen de pleni- tud profesional, de un tiempo en el que la escuela estaba en armonía con los alumnos y con la sociedad, los profesores no cesan de definirse con respecto a una figura idealizada de ellos mismos. ${ }^{28}$
}

El declive del ideal de la escuela es percibido por los maestros como una caída, y su trabajo es cada día una actividad más pesada y al mismo tiempo menos reconocida, pero además sienten que les es imposible cambiar a los estudiantes, a sus familias y al ambiente cultural y social. Los estudiantes, por su parte, cuestionan la utilidad social de la formación que propone la escuela, el sentimiento de utilidad de los estudios no constituye un factor de cohesión y de integración en la vida escolar. La experiencia colegial está dominada por la afirmación progresiva de un principio de subjetivación adolescente opuesto a las lógicas escolares.

\begin{abstract}
La subjetividad de los colegiales se forma en el seno de múltiples estratos. Los grandes y los pequeños, los muchachos y las chicas, los buenos y los malos alumnos rompen la continuidad de las categorías escolares y de las identidades personales. Pero ninguno de los elementos que forman la experiencia colegial es verdaderamente estable: ni la conformidad con las normas escolares, ni la utilidad percibida de los estudios, ni la identidad personal. La experiencia colegial está dominada por las diferencias de estratos y tensiones. ${ }^{29}$
\end{abstract}

Si en los docentes han influido los cambios que se han dado en la escuela, hay que decir que dichos cambios han influido todavía más en los estudiantes, pues la cultura moderna valora al individualismo y a la expresión de sí, el derecho inalienable de afirmar una especificidad personal, sexual,

28 Francois Dubet, y Danilo Martuccelli, "En la Escuela”, 39.

29 Francois Dubet ¿Mutaciones Institucionales y/o Neoliberalismo? En Gobernabilidad de los Sistemas Educativos en América Latina. (Buenos Aires: Instituto Internacional de Planeamiento de la Educación. UNESCO. 2004), 202-215. 
étnica, moral. En los estudiantes de hoy es muy frecuente la manifestación de un proceso de individualización que supone la libertad de conciencia y la apertura a mayores espacios en las dimensiones personales y las emociones, en el caso de la escuela, la adaptación del adolescente a sus funciones de estudiante suele producirse de una manera que muchas veces favorece en gran medida estas tensiones personales, porque cuanto más intensa y multilateral es la regulación de los instintos necesarios para el cumplimiento del papel y las funciones del adulto en una sociedad, mayor es la distancia entre el comportamiento del niño y del adulto. Es común, hoy entre los adolescentes e incluso niños que asisten a la escuela, un reclamo y una exigencia por la autenticidad; esto obedece a la adaptación a una sociedad racionalizada, en la cual los individuos disminuyen el ajustamiento de su comportamiento, de sus objetivos y de sus ideales a la vida en grupo. ${ }^{30}$

Algunos comportamientos de los estudiantes que en el entorno escolar toman forma de rebeldía o apatía, en nombre del libre desarrollo de la personalidad y de su individualidad, son producto de los cambios que ha producido la misma modernidad, pues el estudiante, en este caso como individuo, tiene hoy en día la conciencia de ser una persona autónoma, gobernada por sí misma, distinto de los demás en variados aspectos, en las instituciones educativas donde se dan una multiplicidad y variabilidad de relaciones personales, la defensa de la identidad y de la autonomía de los adolescentes está marcada por el conflicto con los adultos.

Estas exigencias y estos reclamos de libertad, justicia, igualdad, respeto a la intimidad y a la individualidad, entre otros, son vividos por maestros y directivos de muchas instituciones como una crisis, a su modo de ver la institución escolar perdió el carácter sagrado, para convertirse en un servicio, de hecho así es descrita en la Ley General de Educación, cuya utilidad se discute en detalle y se mide progresivamente. Entre los maestros se impone progresivamente la idea de que las dificultades de la escuela provienen de una suerte de "complot" o de proyecto ultra liberal, que consiste en englobar a la educación en el vasto movimiento de mundialización y de este modo asimilar la escuela a la industria, por ejemplo, el hecho de que algunos organismos internacionales demanden una liberalización de la oferta escolar es suficiente como prueba para los maestros.

30 Norbert Elías. La Civilización de los Individuos. (Barcelona: Editorial Península, 1990), 67. 
Esta creencia también se basa en el hecho de que la vieja alianza entre la escuela y la sociedad se ha vuelto más frágil y que, como los efectos desastrosos de las mutaciones económicas se deben a la globalización liberal, se hace creible pensar que la escuela se ve afectada por el mismo movimiento. ${ }^{31}$

La escuela ya no es la instancia de formación por excelencia, pues ha entrado en disputa con otros entes socializadores que han adquirido mucho peso. Entre estos espacios de socialización se destacan los medios de comunicación, prácticas alternas como deportes y artes. También los grupos de pares se han reconocido como un espacio importante de socialización para los niños y para los jóvenes ${ }^{32}$. Las instituciones educativas privilegian por medio de docentes y directivos una mayor valoración de la identidad como nosotros, y en aras de cumplir este objetivo, riñen con la configuración de la libertad del individuo dándole poca valoración positiva. La libertad no es tomada como un valor social sino como un problema que genera ruptura social con ciertos órdenes deseados, en la escuela la búsqueda por dar satisfacción a las necesidades del proceso de individuación por medio del desempeño de roles, genera conflictos que producen tensiones en la vida escolar y enfrentamiento entre sus actores.

\section{Uno de los focos del problema: la disciplina escolar}

La disciplina se refiere a un conjunto de normas o de reglas que se ponen a funcionar dentro del contexto escolar para regular las relaciones entre sus actores, en este sentido la disciplina es considerada como un factor por medio del cual los estudiantes adquieren valores y actitudes que se ven reflejadas en sus acciones en la vida escolar.

En la escuela actual, caracterizada por todos los cambios que se han mencionado y tal vez por muchos otros que faltan por mencionar, "la disciplina" se ha constituido en un eje central dentro de su funcionamiento y ordenamiento administrativo. El problema disciplinario es uno de los factores que ha convertido a las Instituciones Educativas en un espacio de conflicto y permanente lucha entre los docentes, directivos y estudiantes que en ella se relacionan, principalmente porque la escuela de hoy, con todos los cambios

31 Francois Dubet “iMutaciones Institucionales y/o Neoliberalismo?”, 202-215.

32 Ana Lucía Paz, Conflicto en la Escuela, 72. 
que ha tenido, continúa anhelando el modelo de disciplina de antaño, modelo en el cual se buscaba la anulación inmediata del conflicto y en lo posible evitar su aparición. Los conflictos disciplinarios bajo este enfoque no se trataban, se sancionaban normalmente con castigo, era la disciplina como objetivo y como fin. La escuela tradicional es un tipo de organización en donde es considerado bueno aquel comportamiento que no lleva a conflicto de ninguna clase y se premian los comportamientos ejemplares con el reconocimiento por parte de la propia institución escolar, ${ }^{33}$ el tipo de relaciones que se dan dentro de las instituciones educativas ha asimilado la falta de disciplina con la aparición de una conducta conflictiva que influye negativamente en el proceso pedagógico formativo, lo que supone un grave trastorno para el normal desarrollo de la vida escolar.

Algunos de los trabajos que se han realizado en torno a problemas como la disciplina, el conflicto escolar y la organización de la escuela han dado explicaciones a partir de la influencia de factores externos, como problemas familiares y de las comunidades de los estudiantes, es decir, se ha explicado "la llamada crisis de la escuela" por la influencia exterior. Se desconoce la gran repercusión que tiene la misma escuela sobre lo que ocurre en su interior, en este trabajo se plantea que no pocas veces para los docentes y el equipo de dirección, las dificultades pedagógicas y escolares y los problemas de la disciplina parecen escapar del dominio estrictamente escolar.

En este sentido, hay una serie de explicaciones que se pueden considerar como deterministas, donde se naturaliza a los estudiantes, en ellas pueden ser usuales frases como "es que son asi", estas explicaciones que dan los maestros, e incluso algunas investigaciones académicas, carecen de información sobre la cotidianidad de los alumnos, o se basan en teorías que no reconocen la naturaleza diversa de las habilidades de los individuos, este tipo de explicaciones pasan por alto el hecho de que los juicios sobre la capacidad de los alumnos tienen una significación adicional en el contexto escolar y están estrechamente vinculados con la organización del propio establecimiento educativo, por consiguiente, esta explicación de la indisciplina también es diciente de la falta de autoconocimiento de la escuela, sobre el trabajo que se realiza en sus aulas, su organización social, las relaciones entre sus actores, los métodos y recursos para la enseñanza, el currículo. Es muy

33 Serafín Antúnez et al, Disciplina y Convivencia en la Institución Escolar (Caracas: Editorial Laboratorio Educativo, 2000$), 64$. 
común encontrar explicaciones a conflictos disciplinarios de los estudiantes centrados en aspectos de la familia: padres separados, falta de uno de los padres, divorcios, desavenencias conyugales, los que utilizan estas explicaciones acuden generalmente a alguna investigación que justifique su punto de vista, olvidando el amplio abanico de posibilidades que tiene la familia para responder a estas situaciones y enfrentarse a ellas, esto sin tener en cuenta que las explicaciones basadas en el ambiente familiar, rara vez se apoyan sobre un conocimiento real y completo de la familia del alumno.

Las explicaciones que sitúan la causa de los problemas de disciplina en el vecindario se asocian con las características de las familias que viven en la zona a la cual pertenece la escuela, al respecto son valiosos los aportes de Watkins y Wagner, quienes señalan que no todas las escuelas situadas en el mismo vecindario o en otro con similares características se pueden asociar con el mismo tipo de comportamiento, delincuencia, inasistencia a clases, mala conducta, bajo rendimiento por parte de los alumnos, ${ }^{34}$ se puede decir que las explicaciones de la disciplina escolar solo a partir de actores y / o factores externos a la escuela no sirven por sí solas para dar cuenta del problema, y que a su vez se debe incluir en su análisis a la propia escuela. En este trabajo se apunta a señalar la importancia de tener en cuenta explicaciones que no contemplen una sola dimensión, y por el contrario a tener en cuenta patrones más amplios, no solo aspectos personales, referentes al alumno y a su vida, sino también aspectos institucionales, relativos a los profesores, directivos, las clases y la organización escolar.

Tanto las respuestas de los estudiantes como la de los docentes son unilaterales: los primeros enfatizan en el entorno y los segundos acentúan sus respuestas en las relaciones internas de la escuela. Según los estudiantes, la forma como son tratados por los docentes inciden en sus comportamientos; que los docentes no los traten de manera adecuada y no los escuchen provoca reacciones de los alumnos que son catalogadas como indisciplina. En la opinión de los estudiantes sí aparece claramente que situaciones del entorno escolar, actitudes y acciones de los docentes, los métodos de enseñanza, decisiones administrativas como cambios de personal, y reorganización de espacios inciden en los comportamientos de los alumnos.

34 Chris Watkins y Patsy Wagner. Disciplina Escolar (Barcelona: Editorial Paidós. Barcelona, 1991), 83. 
En este trabajo no se defienden ni se atacan las diversas posiciones, lo que se pretende es destacar la multicausalidad del problema, sin desconocer los aportes de trabajos que plantean que las variables que influyen sobre el comportamiento de los estudiantes en las escuelas deben buscarse en tres dimensiones: evolutiva, esto es, el proceso de desarrollo socio moral y emocional en relación con el tipo de relaciones que los estudiantes establecen con sus iguales; psicosocial, que implica las relaciones interpersonales, la dinámica socio afectiva de las comunidades y los grupos dentro de los que viven los alumnos, las complejidades propias del proceso de socialización de los niños y los jóvenes, ${ }^{35}$ aquí se quiere resaltar la importancia de la dimensión educativa, que incluye la configuración de los escenarios y las actividades en que tienen lugar las relaciones entre iguales, el efecto que sobre dichas relaciones tienen los distintos estilos de enseñanza, los modelos de disciplina escolar, los sistemas de comunicación en el colegio y en el aula, el uso de la autoridad y el clima socio afectivo en que se desarrolla la vida escolar.

La dimensión educativa tiene mucha importancia, puesto que resulta fundamental identificar qué aspectos de la vida del aula y de la escuela tienen una incidencia en la configuración de las relaciones interpersonales de los alumnos, y en los modelos y patrones de comportamientos que reflejan. En otras palabras, no se desconoce que el comportamiento que se adopta en la escuela está determinado por variables sociales y familiares, pero en este trabajo se pone el énfasis sobre las variables escolares, se subraya la existencia de variables internas, que parecen estar positivamente relacionadas con los comportamientos que asumen los estudiantes, partiendo del principio que señala que es sobre las variables estrictamente escolares donde la escuela tiene mayor campo de acción

\section{El conflicto disciplinario}

En este trabajo se entiende el conflicto disciplinario como las tensiones, desacuerdos y discrepancias que se presentan entre los estudiantes, docentes y directivos, en torno al concepto, la importancia y los mecanismos utilizados para lograr que haya disciplina en las Instituciones Educativas.

35 Rosario Ortega. "Violencia Interpersonal en los Centros Educativos de Enseñanza Secundaria. Un estudio sobre maltrato e intimidación entre compañeros" Revista de Educación 304, (1994): 255. 
Aquello que los docentes y directivos consideran "falta de disciplina" en los estudiantes es una de las causas que genera conflicto en los centros educativos, a esta situación se suma que en las instituciones se han presentado cambios en la percepción que se tenía del maestro y de su autoridad como algo natural e indiscutido. El adolescente de hoy no tiene la misma percepción sobre la importancia de la escuela, y la utilidad de los estudios, para ellos las instituciones constituyen mundos complejos donde existe una diversidad de actores con intereses y "capacidades" diferentes. La "omnipotencia" del maestro tiende a ser sustituida por la exigencia de reciprocidad y justicia, la relación profesor alumno ya no es unidireccional (el profesor ya no tiene todo el poder, mientras el alumno obedece). Por lo anterior, la experiencia escolar se convierte a menudo en una frontera donde se encuentran y enfrentan diversos universos culturales, esta situación es fuente de conflicto en la escuela.

El cambio en el equilibrio de poder entre los niños, los jóvenes y los adultos es otro factor que puso en crisis los viejos dispositivos que organizaban la vida de las instituciones escolares y además es una de las causas del conflicto disciplinario. ${ }^{36}$ La edad siempre fue un principio estructurador de las relaciones de dominación en todas las sociedades y durante la segunda mitad del siglo XIX, cuando se sentaron las bases de los sistemas educativos, la relación de poder entre las generaciones era mucho más asimétrica que en la actualidad. El mundo de los adultos (los padres, los maestros, los directivos,) prácticamente monopolizaba el poder en las instituciones. Los alumnos tenían más deberes y responsabilidades que derechos, los reglamentos y dispositivos disciplinarios de los establecimientos escolares constituían una objetivación del poder omnipotente que tenían los adultos sobre las nuevas generaciones.

Otra de las causas del conflicto disciplinario son las fuertes críticas de los estudiantes a la disciplina escolar, esta es considerada como innecesaria y excesiva, la oposición al docente y a la disciplina es permanente, a los ojos de los alumnos la organización del colegio es la entrada en un universo normativo complejo, donde la autoridad ya no basta para fundar la legitimidad de las normas.

36 Emilio Tenti Fanfani. “Culturas juveniles y cultura escolar”, 16 
La tensión entre los profesores y los alumnos se presenta por una parte, porque las normas escolares exigen, psicológicamente hablando, un proceso de identificación con el profesor, con sus ideas y con sus acciones, que impulsa a actuar bien en clase con el fin de gustar, y tener buen comportamiento, posición que es también defendida por algunos padres. Por otra parte, las normas del mismo grupo de pares, que permiten la independencia frente a adultos profesores, confieren el reconocimiento de los semejantes. ${ }^{37}$

Los puntos de vista de los actores educativos evidencian que la diversidad de los conflictos que se presentan y que se asocian con la "falta" de disciplina de los estudiantes están relacionados con diferencias en la percepciones e ideas que los adultos tienen del joven y los jóvenes de los adultos, entre los valores establecidos por las generaciones anteriores (los adultos) y la aparición de nuevos valores de las actuales generaciones (los estudiantes). Es latente la falta de canales comunicativos que permitan tramitar por medio del diálogo las dificultades que se presentan en la vida escolar, por eso para algunos estudiantes los docentes recurren permanentemente a decisiones que son autoritarias, y para los docentes la escuela se ha convertido en un espacio donde cada vez es más difícil lograr gobernabilidad.

Sin negar la existencia de espacios de mediación, y el establecimiento de relaciones de solidaridad y fuertes lazos afectivos entre los actores escolares, es una característica permanente la tensión, la ruptura entre el mundo de los adultos y el de los jóvenes. La llamada indisciplina es producto de las fricciones entre el grupo de pares y las exigencias del colegio. Los estudiantes se enfrentan, por una parte, a las normas escolares que exigen un proceso de acoplamiento con lo que el profesor y la escuela persiguen y, por la otra, a un proceso de asimilación con las normas que el mismo grupo de pares produce, y que llaman a la independencia frente al grupo de adultos, los docentes y directivos del colegio. Las tensiones y los desajustes entre las exigencias de la escuela, la preocupación por la subjetivación, y los intereses escolares son tales que los colegiales se dividen haciendo juicios y críticas que pueden parecer contradictorios, decir algo y lo contrario, dando la impresión de no saber qué quieren verdaderamente. La diferencia en la manera como ven el conflicto disciplinario los estudiantes y los docentes permiten ver percepciones

37 Francois Dubet “¿Mutaciones Institucionales y/o Neoliberalismo?”, 28. 
diferentes de la vida escolar y, como se señalaba anteriormente, una fuerte división de criterios que podría ser leída como contradictoria, pero que puede ser, más bien, indicador de la forma como cada actor vive y construye su experiencia escolar, también hay indicios de un ambiente de polarización que viven las instituciones. En cualquier caso, lo que sí es evidente es que nos enfrentamos a una crisis del imaginario adulto, respecto a los modelos tradicionales de interacción, con las nuevas formas de relación de los jóvenes y adolescentes que asisten al colegio. ${ }^{38}$

A esto se le suma que las normas para "mejorar la disciplina" ya no tienen valor en sí y, para lograr un orden absoluto e inalterable, los alumnos han sido provistos de todo tipo de derechos que además se les han hecho conocer por diferentes vías, derechos que son reclamados y puestos en funcionamiento en todo tipo de establecimientos educativos y en todos los grados. El reconocimiento de derechos a los adolescentes aunado a la erosión de las instituciones escolares están en el origen de la crisis en la autoridad pedagógica y por ende en los conflictos disciplinarios. En las condiciones actuales, los agentes pedagógicos (maestros, directivos, expertos, etc.) no tienen garantizada la escucha, el respeto y el reconocimiento de los jóvenes. Pero la autoridad pedagógica, entendida como reconocimiento y legitimidad sigue siendo una condición estructural necesaria de la eficacia de toda acción pedagógica. El punto es que hoy el maestro tiene que construir su propia legitimidad entre los jóvenes y adolescentes, los maestros no pueden dar por descontada su autoridad sino que la tienen que construir en forma cotidiana, de manera que los estudiantes puedan darle sentido a la experiencia escolar.

En cuanto a la manera como se expresa la existencia del "conflicto disciplinario", se puede decir que hay insistencia de los docentes y directivos por mantener "el control" de esta, ante lo cual surge un reto de poderes y hostigamientos con los estudiantes, los unos por hacer cumplir la norma y los otros por evadirla. ${ }^{39}$ Los docentes, por su parte, dicen estar aburridos de llenar documentos que evidencien la falta de disciplina de los estudiantes, porque para ellos el problema no radica en el diligenciamiento de dichos documentos, las fallas radican para los docentes, en particular, en que el Consejo Directivo y los directivos (coordinadores y el rector) no imponen

38 Américo Calero. Escenas de la vida escolar. La cotidianidad, sus dramas y comedias. serie convivencia y democratización de la vida escolar. (Santiago de Cali: Universidad del valle. Alcaldía Municipal, 2005), 96

39 Luís Marino Mejía. William Valencia. La escuela reforzadora de la violencia. (Armenia: FES. Universidad del Quindío, 1992 ), 171. 
sanciones ejemplarizantes cuando los estudiantes indisciplinados llegan a esta instancia y, en general, en las libertades ilimitadas que la ley ha dado a los alumnos.

\section{CONCLUSIÓN}

La escuela de hoy compite, en creciente desventaja, con otras fuentes de socialización y los estudiantes son influidos por otros modelos, a esto se suma que la institución no encuentra cómo exponer a los estudiantes otras alternativas simbólicas, tanto o más seductoras, ni aprovecha sus espacios y tiempos para criticar y debatir sobre lo negativo e incorporar lo positivo que también existe de otras influencias. ${ }^{40}$ Mientras algunos docentes han dado muestras de incorporar en su trabajo elementos de esas otras formas de socialización como la televisión, la red de Internet y la música, otros son muy críticos frente a estos, destacando su influencia negativa en los niños y jóvenes, por considerar que los incitan a la violencia, a la sexualidad sin afecto y en general, a llevar una vida superficial y banal.

En la escuela -cuyo programa institucional entra en crisis- eran funciones básicas el control social de los niños y jóvenes y la invención de procesos colectivos para el desarrollo de un conjunto de aprendizajes básicos tanto comportamentales como intelectuales, este tipo de institución se caracterizaba entre otras cosas por una fuerte estructura jerárquica, autonomía en la selección de los alumnos, autonomía en la operación cotidiana sobre la base de la autoridad de los maestros sobre los alumnos, tendencia a la homogenización de los estudiantes de acuerdo con categorías de grado, edad, capacidad y origen social, estandarización de programas, calendarios y modalidades de enseñanza.

Puede señalarse entonces que a los maestros y a los planificadores de la educación les ha faltado, una comprensión más amplia de lo que está ocurriendo dentro de la escuela, la escuela del siglo no podía sobrevivir frente al fortalecimiento de la crítica y de la autonomía individual, que también participan plenamente del proyecto mismo de la modernidad, no se ha podido sostener su carácter sagrado, cuando al mismo tiempo se admite que la realización y la libertad de los individuos para construir la vida que mejor

40 Américo Calero. Escenas de la vida escolar. La cotidianidad, 98 
les parece constituyen uno de los esfuerzos de la modernidad, sobre todo cuando la misma escuela se constituyó en promulgadora de esos valores, el programa institucional se quedó sin uno de sus fundamentos más sólidos porque el proyecto cultural de la escuela moderna triunfó.

La democratización de la vida escolar es un intento por promover una cultura democrática donde haya participación de todos los actores escolares en la construcción de planes y programas que ayuden a lograr un mejor clima institucional, calidad en la enseñanza, estrategias para resolver conflictos $\mathrm{y}$, en general, a lograr una buena convivencia con calidad académica. De esta manera, la Ley general de Educación y sus decretos reglamentarios buscan modificar las formas tradicionales de organización y de dirección de las instituciones educativas caracterizadas por la centralización del poder, por la existencia de formas autoritarias de gestión y por la escasa posibilidad de interacción de estudiantes y padres de familia en los asuntos de la institución. ${ }^{41}$

El gran reto de la democratización ha sido pasar de instituciones caracterizadas por formas de organización relativamente verticales, con un rol dominante de la figura del rector y un estamento relativamente intocable como el docente, a una nueva forma de organización donde los actores excluidos como padres y estudiantes tuvieran voz y voto en la planeación y ejecución de actividades. El nuevo orden escolar que busca la democratización incluye la división relativa de poderes que descentraliza la toma de decisiones, le pone límites al poder de estos actores tradicionales e incluye sectores antes excluidos en su marcha y proyección. Pero es preciso resaltar que aunque los mecanismos legales están dados para hacer instituciones más democráticas, hay todavía dentro de la comunidad educativa estudiantes, padres de familia y también maestros que no se han apropiado de ellas, no las emplean, no acuden a ellas y dejan de lado la opción de emplearlas para hacer exigencia de derechos que les son negados o sencillamente son omitidos.

Uno de los principales objetivos de democratizar la escuela es pues hacerla participativa, para ello se crean los órganos de gobierno escolar

41 Adolfo Álvarez et al, (2002). Dinámicas y Logros de los Gobiernos Escolares en Instituciones Educativas de Cali. Informe de Investigación (Santiago de Cali: Colciencia. Univalle, 2002), 275. 
que aparecen como actores claves de una nueva institucionalidad que debe plantearse en todos los establecimientos educativos, dichos órganos fueron creados para garantizar la participación de todos los actores escolares, en la gestión y ejecución de planes y programas en la institución. Hoy el interrogante se centra en el alcance, sentido y la profundidad de estos procesos, y el grado en que han logrado los propósitos y la visión propuesta por la normatividad que los creó.

La coyuntura generada por la creación de espacios y escenarios para la participación, la discusión y el consenso dentro de las instituciones educativas, el momento en el cual se pone sobre el tapete la importancia de garantizar el respeto a la dignidad y la supremacía de los derechos humanos en la acción educativa, y el momento en que los hechos mostraron que las expresiones de los estudiantes estaban cambiando de la desobediencia y el mal comportamiento en el descanso o en el aula a la trasgresión de normas que comprometían la integridad física y emocional, hasta llegar incluso al expendio de drogas, robos y actos violentos, son el contexto en el cual se reaviva el debate sobre aspectos de la vida escolar como la norma y la disciplina, cuyo campo de discusión estaba restringido a los directivos y los docentes.

La disciplina es hoy un punto central en la vida de las instituciones educativas, lo que los maestros y directivos denominan "indisciplina" los enfrenta día a día con los estudiantes, según estos, porque los maestros quieren mantener un modelo disciplinario que no es acorde con el tiempo en el cual ellos viven, y según los maestros porque los estudiantes usan y abusan de los derechos que les ha otorgado la Ley para no acatar las normas y hacer su voluntad en las instituciones.

En este trabajo no se niega que el problema disciplinario y normativo que se vive en los establecimientos educativos tenga algunas influencias del mundo familiar y social donde viven los estudiantes, pero se hace énfasis en la capacidad de la institución para abordar y tratar el problema con herramientas educativas, se parte de la convicción de que aspectos como la naturaleza de las reglas de la escuela, el sistema de sanciones y castigos que se utiliza, el cuidado del bienestar de los alumnos, los estilos de liderazgo adoptados por la dirección, los coordinadores y los maestros, la 
actitud hacia los problemas sociales y académicos de los estudiantes, así como la filosofía general y los valores de la escuela, desempeñan un papel importante en las relaciones que se establecen entre los actores escolares.

La indisciplina o falta de disciplina es un factor que crea conflicto en las escuelas y colegios. En este trabajo entendemos el conflicto disciplinario como las tensiones, desacuerdos y discrepancias que se presentan entre los estudiantes, docentes y directivos en torno al concepto y los mecanismos utilizados para lograr que haya disciplina en las instituciones educativas. Las situaciones que originan dicho conflicto son variadas, pero sobresale la exigencia del cumplimiento de los derechos que la Ley ha dado a los estudiantes, la exigencia de libertad y autonomía, y muy especialmente un elemento nuevo en la relación entre docentes directivos y estudiantes, la exigencia de estos últimos de reciprocidad, igualdad y justicia en el cumplimiento de derechos y deberes dentro de la institución.

Lo que se quiere subrayar es que la dimensión educativa tiene mucha importancia, puesto que resulta fundamental identificar qué aspectos de la vida del aula y de la escuela tienen una incidencia en la configuración de las relaciones interpersonales de los alumnos, y en los modelos y patrones de comportamientos que reflejan. En otras palabras, no se desconoce que el comportamiento que se adopta en la escuela está determinado por variables sociales y familiares, pero en este trabajo se pone el énfasis sobre las variables escolares, se subraya la existencia de variables internas, que parecen estar positivamente relacionadas con los comportamientos que asumen los estudiantes, partiendo del principio que señala que es sobre las variables estrictamente escolares donde la escuela tiene mayor campo de acción.

El tema de la disciplina crea tensiones en la institución educativa, no hay unidad de criterios entre los docentes, los directivos y los estudiantes ni en su definición, ni en su importancia, ni en los medios para conseguirla. Cada uno define la disciplina influenciado por lo que ha determinado la institución o por su propia subjetividad, demostrando que los actores escolares ya no siguen tal cual lo que la institución propone, sino que toman aquello que les es útil y frente a lo demás toman distancia. Las diferencias frente al concepto de disciplina, su importancia y la manera más adecuada de llegar a ella producen tensiones y desacuerdos entre los miembros de la comunidad educativa. El conflicto se hace complejo por 
la introducción de un elemento nuevo en la vida escolar, el reclamo de los estudiantes de reciprocidad e igualdad en el cumplimiento de los derechos y deberes, reclamos que se acompañan con comentarios en los que si bien se reconocen fallas en algunos comportamientos de los estudiantes, también se responsabiliza a los docentes y directivos de asumir actitudes y llevar a cabo acciones que propician la indisciplina.

Los conflictos disciplinarios se dan de la mano con el hundimiento de valores tradicionales, una ética de la racionalidad, una fuerte tendencia al individualismo y una universalización de los derechos humanos promovida por los medios de comunicación de masas que han aumentado la pluralización de distintas creencias y valores. Estos cambios que los jóvenes estudiantes tienen y que provocan choque con la institucionalidad de la escuela hacen parte de lo que Norbert Elías llama el equilibrio entre el nosotros y el yo, que puede ser interpretado como la relación entre las identidades colectivas y la formación de una identidad individual. ${ }^{42}$

Un punto central en el conflicto disciplinario es el de las normas, el aparato normativo que regula el comportamiento de los miembros de las instituciones. Las normas sirven como orientación de la manera de comportarse de cada miembro de determinado grupo, pero si bien cada institución crea dichas normas como medio para regular las relaciones de sus miembros, esto no da seguridad que dichos miembros compartan estas normas y se acojan a ellas, en los colegios y escuelas de hoy se presenta precisamente esta situación. La existencia de las normas no asegura, ni que se acepten, ni que se compartan y menos que se cumplan, dando lugar a que se presente el conflicto por la manera como son concebidas y aplicadas. En este estudio las normas se entienden como las reglas establecidas por los grupos para regular la conducta de sus miembros, tales reglas, pueden ser explícitas o implícitas e indican a los miembros del grupo cómo comportarse y cómo no comportarse

Desde sus inicios la escuela ha creado normas cuyo objetivo es propiciar modelos para la formación de los individuos, durante mucho tiempo estas normas fueron captadas y aceptadas por la mayoría de los individuos sin cuestionamientos o exigencia de participación en su creación, situación que

42 Norbert Elías. La civilización de los individuos, 70. 
sí es latente en la actualidad en la escuela. Los estudiantes de hoy se oponen fuertemente a las normas, les dirigen sus críticas por considerarlas excesivas, poco formativas y que coartan su autonomía y su libertad, pero también se oponen a lo que llaman el abuso en su aplicación por parte de los maestros y su uso arbitrario. El panorama es el de un conflicto latente donde unos intentan hacer cumplir las normas y otros las trasgreden de manera reiterativa. Aspectos como la forma de vestir, los horarios y el uso de espacios siguen siendo puntos sobre los que estudiantes y docentes no logran ponerse de acuerdo, por el contrario, generan tensión que en algunos casos llega a convertirse en rivalidades, la exigencia de aquello que es considerado como un derecho. El libre desarrollo de la personalidad ha invadido las instituciones educativas, en su nombre los estudiantes asumen diversidad de actitudes y ejecutan diversidad de acciones incluso delincuenciales que ponen en peligro su integridad y la de otras personas, situación ante la cual los docentes culpan al Estado por lo que consideran permisividad y flexibilidad en la normatividad establecida.

A manera de resumen, hay que acotar que en un contexto en el que la escuela ya no es la institución formadora por excelencia y aquello que plantea el ideal de educación no necesariamente es lo que ocurre en los establecimientos educativos. La relación entre las concepciones y las formas de funcionamiento de la disciplina, la norma y la democracia son claves en la organización social de las instituciones, puesto que aquellas donde existe relativa coherencia entre el discurso y la práctica y claridad en los principios y planteamientos esenciales que fundamentan su funcionamiento tienen mayor capacidad de resolver los conflictos que puedan surgir entre los actores que en ellas se relacionan.

Sobre este último punto hay que decir que se ha avanzado a distintos ritmos en el país, hay instituciones que se han mostrado mucho más abiertas y con mejor disposición para transformar sus prácticas al adoptar nuevos modelos pedagógicos y material didáctico innovador en el área de ciencias sociales, de manera que no solo se transforme el proceso enseñanza aprendizaje, sino también las relaciones escolares. Sin embargo, hay también instituciones en las cuales las prácticas pedagógicas, tanto en la forma de enseñar como en las relaciones sociales, siguen amarradas a la escuela tradicional. En el campo de los libros de texto de geografía hay que destacar principalmente su apertura, más bien su diseño y puesta en circulación, ya que durante 
mucho tiempo la geografía estuvo a la sombra de la historia, de modo que en los libros de texto la enseñanza geográfica ocupaba una muy mínima parte al lado de la enseñanza de la historia. Hoy, muchos libros de texto contemplan solamente la enseñanza de la geografía, y aunque haya todavía muchos aspectos metodológicos a mejorar en dichos libros, es ya un avance que existan libros para la enseñanza de la geografía, el reto en los libros de texto está precisamente en lograr el enfoque de la enseñanza de la geografía desde la perspectiva actual y moderna de la ciencia.

Finalmente hay que señalar que los resultados del estudio abren la posibilidad de abordar, ampliar y profundizar sobre otros problemas de investigación como la degradación de la autoridad de los maestros y directivos; el poco valor y la falta de expectativas que tiene la educación para algunos jóvenes; la utilidad de las concepciones que tienen los actores sobre el conflicto escolar para buscar soluciones a este.

\section{FUENTES}

Ministerio de Educación Nacional. Estándares básicos de competencias en ciencias naturales y en ciencias sociales. Bogotá: Ministerio de Educación Nacional, 2003.

Ministerio de Educación Nacional. Plan Decenal de Educación 1996-2005. Bogotá: Ministerios de Educación Nacional, 2006.

Ministerio de Educación Nacional. Programas estructurados nacionales para el desarrollo de las competencias ciudadanas. Bogotá: Minsterio de Educación Nacional, 2003.

Ministerio de Educación Nacional. Reforma Educativa y Proyecto Educativo Nacional. Reinvención de la Institución Escolar. Informe al Congreso Nacional. 1994-1998. Bogotá: Ministerio de Educación Nacional, 1998.

Manual de convivencia de la institución educativa

Proyecto Educativo Institucional (PEI) de la institución educativa

\section{REFERENCIAS}

Aguilar, Juan Francisco y José Javier Betancourt. Construcción de una Cultura Democrática en Instituciones Educativas de Santa Fe de Bogotá. Bogota: Idep-Innove, 2002.

Álvarez, Adolfo, Javier Monedero, Amparo Pereira. Dinámicas y Logros de los Gobiernos Escolares en Instituciones Educativas de Cali. Santiago Cali: Informe de Investigación Colciencia, Univalle, 2002. 
Antúnez, Serafín, Carmen Boque, Gregorio Casa Mayor, Pedro Fajardo. Disciplina y Convivencia en la Institución Escolar. Caracas: Editorial Laboratorio Educativo, 2000.

Ball, Stephen. La Micro política de la Escuela. Hacia una Teoría de la Organización Escolar. Barcelona: Editorial Paidós, 1989.

Brunner, José Joaquín. Educación e Internet. ¿La próxima revolución? Santiago de Chile: Fondo de Cultura Económica, 2003.

Cajiao, Francisco. Poder y Justicia en la Escuela Colombiana. Vida Escolar en Colombia. Bogotá: Fundación FES, 1994.

Calero Llanes, Américo. Escenas de la Vida Escolar. La cotidianidad, sus dramas y comedias. Serie convivencia y democratización de la vida escolar. Santiago de Cali: Universidad del valle. Alcaldía Municipal, 2005.

Castro, Jorge Orlando. Universidad Pedagógica. Centro de Investigaciones CIUP. Apuntes sobre la extensión de la tecnología educativa y el modelo curricular en el Distrito. Historia de la Educación en Bogotá, Alcaldía Mayor de Bogotá, Instituto para la Investigación Educativa y el Desarrollo Pedagógico -IDEP. Bogotá: Panamericana Formas e Impresos S.A, 2002.

Colombia. Constitución Política de Colombia. Bogotá, 1991.

Cubides, Humberto. "Gobierno Escolar: Cultura y Conflicto Político en la Escuela". Revista Nómadas 15 (2005): 17-28.

Departamento Nacional de Planeación. Dirección de Desarrollo Social. www.dnp.gov.co.

Dubet, Francois). “¿Mutaciones Institucionales y/o Neoliberalismo?”. En Gobernabilidad de los Sistemas Educativos en América Latina. Instituto Internacional de Planeamiento de la Educación, Buenos Aires: UNESCO, 2004.

Dubet, Francois, Danilo Martuccelli. En la Escuela. Sociología de la Experiencia Escolar. Buenos Aires: Editorial Losada, 1997.

Durkheim, Emilio. Educación y Sociología. Bogotá: Editorial Babel, 1976.

Durkheim, Emilio. La Educación Moral. Buenos Aires: Editorial Shapire.1992.

Elías, Norbert. La Sociedad de los Individuos. Barcelona: Editorial Península, 1990.

FES. Colciencias. Proyecto Atlántida. Informe Final. Bogotá: Colciendias, 1995.

Frigerio, Graciela, Margarita Poggi, y Mario Giannoni (Compiladores). Políticas Institucionales y Actores en Educación. Centro de Estudios Multidisciplinarios. Colección Reflexión y Debate. Buenos Aires: Ediciones Novedades Educativas, 1997.

Gómez, Hernando. Educación La Agenda del Siglo XXI Hacia un Desarrollo Humano. Programa de Naciones Unidas para el desarrollo. Bogotá: Tercer Mundo Editores, 1998. 
Jares, Xesús. "El lugar del Conflicto en la Organización Escolar" Revista Iberoamericana de educación 15 (1997): 35-40.

Ortega Rosario. "Violencia Interpersonal en los Centros Educativos de Enseñanza Secundaria. Un estudio sobre maltrato e intimidación entre compañeros". Revista de Educación (1994): 250-265.

Paz, Ana Lucía. Conflicto en la Escuela, Configuración de Espacios de Mediación. Alcaldía Municipal. Cali. Santiago de Cali: Universidad del Valle, 2005.

Ramírez, María Teresa, y Juana Patricia Téllez,. La educación primaria y secundaria en Colombia en el siglo XX. Bogotá: Unidad de Investigaciones de la Gerencia Técnica del Banco de la República, 2006.

Tenti Fanfani, Emilio. “Culturas juveniles y cultura escolar".IIPE/UNESCO.Sede Regional Buenos Aires 2000 Nombre completo del seminario, Lugar donde fue realizado el seminario. Fecha.

Watkins Chris, Wagner, Patsy. Disciplina Escolar. Barcelona: Editorial Paidós, 1991.

Palacios Mena, Nancy. “Transformación y crisis de la escuela: algunas reflexiones sobre el caso colombiano". Revista Historia de la Educación Latinoamericana. Vol. 15 No, 21, (2013): 335 -375. 


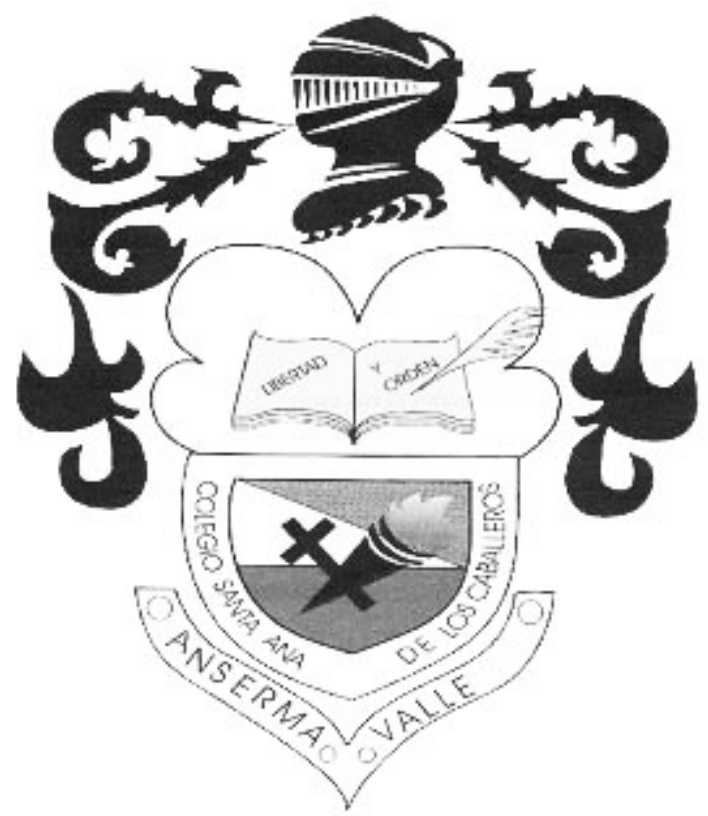

Escudo que identifica la institución Educativa, en la cual se realizó la investigación que da origen al artículo que se presenta en la revista. 